\title{
El empresariado mexicano en perspectiva
}

\author{
Arzuaga Magnoni, Javier (2004), Racionalidad EMPresarial. Los \\ MEGAEMPRESARIOS MEXICANOS, GERNIKA-FACULTAD DE CIENCIAS \\ Políticas,Universidad Autónoma del Estado de México, Toluca, \\ MÉxICO, 478 PP., ISBN: 970-637-009-9.
}

El interés particular de los empresarios por participar en la política en los últimos 25 años y su creciente importancia en la definición de las políticas económicas de los gobiernos en turno ha sido motivo de un cúmulo de investigaciones que explican esta relación. Sin embargo, tienen como denominador común interpretaciones economicistas, atribuyen a los empresarios una gran autonomía respecto de otros actores e instituciones y mediante conceptos de "hegemonía", "bloques de poder" y "pactos", que aluden a distintos niveles de abstracción y de difícil o nula operatividad en el análisis. Estas preocupaciones guían el trabajo de Javier Arzuaga Magnoni, Racionalidad empresarial. Los megaempresarios mexicanos, cuya propuesta se traduce en la construcción de un marco de análisis complejo para explicar el comportamiento de los grandes empresarios mexicanos.

En este sentido, Arzuaga Magnoni discute la autonomía y aislamiento a partir de las cuales se estudia la acción del empresario como un actor político, pues las perspectivas realizadas juzgan como contradictorias las decisiones empresariales frente a su ambiente. Para el autor, ese ambiente no es algo simple, sino que está formado por limitantes y restricciones que se presentan como establecidas para los empresarios, esto es lo que forma y define al conjunto de oportunidad; oportunidad en la medida que ofrece una gama de opciones disponibles para ser enfrentadas por el megaempresario de manera racional.

Para el megaempresario, dice el autor, son importantes cuatro mediaciones a través de las cuales fluyen sus relaciones en su propósito deliberado de activar y valorar el capital: la empresa, el empresariado, el mercado y el sistema político-gobierno. Estas mediaciones son pertinentes en la medida que los megaempresarios forman parte de una categoría genérica que el autor denomina el ser-empresario, que se define principalmente por la explotación de la fuerza de trabajo y la valoración constante del 
capital. La primera se constituye en la finalidad del ser-empresario, la condición de su existencia y a la vez su límite.

La forma específica que adquiere la relación entre el ser-empresario y la explotación de la fuerza de trabajo y valoración del capital es lo que determina el patrón de acumulación, entendido como la forma de organización productiva, de gestión gubernamental hacia los empresarios y las empresas, y las políticas públicas implantadas por el gobierno.

Consecuencia de lo anterior y considerando la reconstrucción de coyunturas específicas mediante un esquema de racionalidad empresarial, según el autor, puede explicarse el sentido de la acción política de dicho actor social. Al igual que otros actores sociales, los megaempresarios están sujetos a los contratiempos de no contar con información suficiente para la toma de decisiones. Eligen sus cursos de acción de forma óptima, pero limitada por las mediaciones y una lógica de capital que trascienden su voluntad individual de elección. Aun así, tienen la posibilidad de elegir dentro de una gama de opciones lo que mejor convenga a sus intereses.

Para demostrarlo en el caso específico de México, el autor organiza el trabajo en tres partes. La primera de ellas, denominada "Racionalidad empresarial. Un marco de análisis", describe las principales categorías utilizadas a lo largo del texto, como son: conjuntos de oportunidad, racionalidad, empresario, lógica de capital, patrón de acumulación, entre otros. También se define a la acción empresarial como la expresión singularizada de la lógica del capital. Arzuaga menciona que se concreta cuando al sujeto empresario se le presentan restricciones o conjunto de oportunidad, al cual se enfrenta de forma racional optimizando sus recursos y conocimientos para actuar de mejor manera en un patrón de acumulación específico. Utilizando nociones marxistas, explica que la determinación genérica del ser-empresario es la explotación de la fuerza de trabajo como proceso permanente de valoración del capital. De aquí que se imponga al empresario su finalidad, la condición de su existencia, pero a su vez el límite, lo cual explica el carácter de conflictividad inherente del patrón de acumulación.

En la segunda parte, llamada "El capitalismo en perspectiva", se caracteriza el modelo taylorista, fordista y keynesiano (TFK) como un modo de acumulación de capital que demandaba ciertas relaciones con el Estado para asegurar el sometimiento del trabajo al capital, así como las áreas problemáticas que implica- 
ba esta forma específica de producción. También se describe su concreción en México y América Latina mediante el modelo de sustitución de importaciones (ISI), pero sin desconocer un modelo primario exportador (PE) para esta región. Se analiza el caso mexicano detallándose sus particularidades, pero se reconoce que forma parte del modelo TFK, aplicado en el mundo durante esa época, cuyos frutos más visibles fueron expresados en el "milagro mexicano". No obstante estos frutos positivos, el autor considera que la propia configuración del modelo era contradictoria, lo que con el tiempo se manifestó por medio de desequilibrios macroeconómicos y descontentos políticos y sociales.

Según el autor, los escenarios posteriores al estallido de la movilización social de 1968 muestran ampliamente el conflicto entre capital y trabajo en términos de una puja distributiva entre ambos. La salida del empresariado ocasionó el cambio de las relaciones de fuerza; esta situación detonó una aguda crisis económica y nuevas condiciones para la acumulación. Lo interesante del asunto radica en que esas nuevas condiciones son iguales a las definidas globalmente.

La tercera parte, titulada "Los megaempresarios mexicanos. Estudios de caso", presenta los criterios usados para la selección de las 69 megaempresas y los 1,091 megaempresarios sujetos del trabajo. De igual forma se abordan datos específicos de las empresas seleccionadas, que corroboran su importancia en términos laborales, financieros, productivos, por sector de actividad, localización, fechas de constitución y de participación en la Bolsa Mexicana de Valores (BMV), estrategias de expansión y concentración. De los megaempresarios de la muestra, se detalla que al menos 105 forman parte de más de un consejo de administración de las 69 megampresas analizadas, lo que para el autor es "el núcleo del megaempresariado mexicano", y a su vez indica el grado de concentración en pocas manos del control de la mitad de las megaempresas.

En este tercer apartado también se exponen las relaciones específicas entre los megaempresarios y sus cuatro mediaciones principales -empresa, mercado, empresariado y gobierno/sistema político- que se constituyen en instrumentos y, al mismo tiempo, en límites de la acción empresarial.

En 'Los megaempresarios frente a sus megaempresas', Arzuaga enuncia un conjunto de aspectos que cualquier empresa tiene que resolver por su carácter de organización destinada a la valoración constante del capital; desde los meramente administrati- 
vos (objetivos organizaciones $v s$. objetivos individuales, creciente complejidad de la estructura organizacional, racionalidad limitada de la toma de decisiones dentro de la organización y una contingencia ambiental que obliga a una constante adecuación de las estructuras) hasta los laborales (mecanismos de fijación de salario, de contratación o despido de trabajadores, impuestos, tributos y gravámenes derivados del salario).

El autor afirma que pueden distinguirse claramente tres momentos de la matriz clásica, definida en México como "el patrón contractual de la revolución mexicana": una primera fase de institucionalización, desde la redacción del Artículo 123 constitucional hasta la promulgación de la Ley Federal del Trabajo en 1931; la segunda, caracterizada por la utilización discrecional de la legislación laboral y la consolidación del corporativismo sindical; y la tercera, donde se pone de manifiesto la crisis del patrón y la flexibilización de las normas laborales, hacia la década de los ochenta.

Según el autor, cada fase ha necesitado una forma específica de explotación de la fuerza de trabajo, lo cual ha requerido ajustes necesarios a las normas encargadas de regularla. Particularmente la última fase hizo evidente la crisis del modelo, a partir de mayor resistencia obrera y la caída del ritmo de productividad, pero donde también influyeron factores exógenos como el crecimiento e incorporación de la electrónica, la calidad para elevar la competitividad, la flexibilidad y la informática.

En 'Los megaempresarios frente al mercado', el autor toma una encuesta del Banco Nacional de México -realizada en 1988 con el propósito de revelar sus expectativas económicas y opiniones respecto a la inversión privada y la posición competitiva internacional de las empresas líderes de México-, y consigue destacar que las principales determinantes en la toma de decisiones empresariales están vinculadas con la estabilidad política y económica, las políticas públicas y los marcos jurídicos. Distingue los límites de mediano plazo (régimen fiscal, control de precios, política de control del gobierno, modernización de la infraestructura, trámites excesivos, etc.) y los próximos o de corto plazo (demanda interna y externa, disponibilidad del crédito, investigación y desarrollo, falta de tecnología moderna, entre otros) de los conjuntos de oportunidad del megaempresario mexicano.

Lo trascendente para el objetivo de la investigación es notar cómo, a partir de evidencia obtenida de un conjunto pequeño de megaempresas, el mercado, como mecanismo de intercambio y 
asignación de recursos, no constituye un problema para los empresarios, quienes asumen que las condiciones que les presenta el patrón de acumulación les son dadas a la hora de afrontar su actividad macroeconómica, por eso operan de manera adaptativa.

'Los megaempresarios frente al empresariado' presenta un recorrido histórico de la instalación de diversas organizaciones empresariales y sus principales logros y dificultades en ciertos periodos; da cuenta de las transformaciones que sufrieron, fusiones y divisiones, así como su papel en el fortalecimiento del primer modelo de acumulación de matriz clásica, y su transformación radical con el modelo neoliberal en los primeros años ochenta. El cambio de patrón de acumulación fue posible debido a la conjugación de la nacionalización de la banca, la crisis económica y, sobre todo, por la ilegitimidad que la acompañó. Esta característica anuló cualquier posibilidad de un regreso, o una política de ajustes sin cambio radical.

Los megaempresarios reconocen la funcionalidad de las cámaras empresariales como representación de sus agremiados, quienes señalan que los asuntos de índole general son gestionados por sus organizaciones empresariales, mientras que los particulares lo son por cada empresa.

A pesar de que no renuncian a su participación política y que dan muestras de actuar colectivamente en momentos de crisis (mediante, por ejemplo, la Confederación Patronal de la República Mexicana [Coparmex], el Consejo Mexicano de Hombres de Negocio [CMHN] y el Consejo Coordinador Empresarial [CCE]), sus declaraciones en los medios de comunicación tienden a ser más de orden técnico que político y aparece, fundamentalmente, en la sección de negocios de los diarios La Jornada y Reforma, según lo revelan las frecuencias observadas por el autor en 1996.

Finalmente, en 'Las megaempresas frente al gobierno', Arzuaga da cuenta de la correspondencia entre las políticas y su influencia en las megaempresas a partir de datos empíricos; utiliza conceptos como "acción política”, "políticas públicas” y "acción organizativa" y muestra, mediante gráficas, la distribución de las acciones de los organismos empresariales por campo, tema y organización.

Aunque en este pequeño apartado el análisis se limita al año 1996, en medio de las repercusiones de la crisis, lo cierto es que los megaempresarios mantienen el perfil de sus apariciones públicas y, además, a diferencia de los ochenta, cuando pugnaban a favor del cambio de patrón de acumulación, critican la gestión 
coyuntural. Esto se explica, dice el autor, porque los megaempresarios evitaron llevar las discusiones a terrenos donde pudiera ser puesto en crisis el modelo neoliberal; ante esa coyuntura vieron con mejores posibilidades adoptar un perfil técnico administrativo para buscar salidas a la crisis sin cuestionar el patrón de acumulación. Sin embargo, mantuvieron en el gobierno su principal fuente de incertidumbre y, sobre todo, en las contiendas político-electorales su principal preocupación: asegurar la continuidad del modelo.

Es pertinente aclarar que este libro no hace una revisión específica y profunda de la racionalidad de los megaempresarios mexicanos, sino del ser-empresario en genérico y los límites que restringen su capacidad de decisión.

Después de esta aclaración, permítanseme unos comentarios finales. El texto presenta varias virtudes para la comunidad académica, y aunque es cierto que todo trabajo tiene límites, éstos son reconocidos por el propio autor al final, cuando menciona que queda en deuda con una explicación más específica y profunda, así como de una evaluación crítica de la aplicación del modelo más allá de los casos abordados.

Aunque no es un propósito deliberado de la investigación, no es difícil darse cuenta de que enriquece la perspectiva de los politólogos interesados en el análisis del sistema político, ya que en la investigación pone en entredicho la disciplina política de los empresarios -y en general de los diversos actores políticos y sociales- y el autoritarismo presidencial durante el siglo Xx en México.

El texto aborda diversos aspectos importantes para los estudiosos de los empresarios en la medida que ha obviado algunos elementos para explicar su actuación al despojarlos de su carácter contradictorio, limitado y condicionado. Arzuaga los coloca en una dimensión justa, realista por cuanto demuestra sus limitantes, pero no por ello sin posibilidades de elección favorable. Si se toma en cuenta que responden a una lógica de capital ajena a su voluntad, que lo define como el ser-empresario, que carga con la "condena perpetua" de explotar la fuerza de trabajo, evitaremos distorsiones a la hora de analizar casos específicos. En suma, los empresarios no son ni más ni menos autónomos para el análisis social y político que el resto de los actores sociales.

Por el enfoque utilizado en la primera parte, donde se habla de capitalismo, el ser-empresario y la lógica del capital, se percibe una lectura marxista, pero el autor se aleja de la afirmación 
de que el Estado sea un aliado de la burguesía "explotadora" porque pone a su disposición el entramado jurídico y político para ese fin. Demuestra que la relación no ha sido unilateral, con rendimientos siempre positivos al empresariado, sino que tiene límites precisos y que, en todo caso, el entramado institucional, jurídico y político otorga márgenes de libertad tanto al empresario como al obrero, aunque los tiempos neoliberales den la impresión de que la resistencia trabajadora está perdida.

Cabe decir que los empresarios no son 'culpables' de la reproducción capitalista y de la pobreza, en realidad son parte de una lógica de capital a la cual se insertan para obtener utilidades, pero sin la cual gran parte del motor del complejo sistema social, con sus avances y problemas, dejaría de funcionar. Quizá habría que preguntarse si los megaempresarios sólo se adaptan al capitalismo y a la lógica del capital, o si le imprimen un estilo particular y crítico, y en esa medida, si es posible y viable, uno más 'humano'.

ORLANDO ESPINOSA Facultad de Ciencias Políticas y Administración Pública, UAEMéx panopticos@hotmail.com

Orlando Espinosa Santiago es maestro en sociología política por el Instituto de Investigaciones Dr. José María Luis Mora y licenciado en ciencias políticas y administración pública por la Universidad Autónoma del Estado de México. Tiene un diplomado universitario en análisis político de la Universidad Iberoamericana. Se desempeña como profesor de asignatura de la Facultad de Ciencias Políticas y Administración Pública y de cursos en el Diplomado sobre Cultura Política y Teorías de la Democracia de la Facultad de Derecho, ambas de la UAEméx. Su publicación reciente $(2005)$ es "Sobre el desencanto de la democracia y la reelección”, revista Apuntes Electorales del Instituto Electoral del Estado de México, Toluca, México, nueva época, año IV, núm. 17, pp. 97-101. Sus líneas de trabajo consisten en caciques, elites, sistema político mexicano y democracia. 